\title{
Oral consequences of obesity and metabolic syndrome in children and adolescents
}

\section{Konsekwencje otyłości i zespołu metabolicznego dla zdrowia jamy ustnej u dzieci i młodzieży}

\author{
Małgorzata Maria Salamonowicz ${ }^{1, A-D}$, Anna Zalewska ${ }^{1, A, E, F}$, Mateusz Maciejczyk ${ }^{2, E}$ \\ 1 Department of Conservative Dentistry, Faculty of Medicine with the Division of Dentistry and the Division of Medical Education in English, Medical University of Bialystok, Poland \\ ${ }^{2}$ Department of Physiology, Faculty of Medicine with the Division of Dentistry and the Division of Medical Education in English, Medical University of Bialystok, Poland \\ A - research concept and design; $B$ - collection and/or assembly of data; $C$ - data analysis and interpretation; \\ $D$ - writing the article; $E$ - critical revision of the article; $F$ - final approval of the article
}

Address for correspondence

Małgorzata Salamonowicz

E-mail:wrobmalg@gmail.com

Funding sources

None declared

Conflict of interest

None declared

Received on November 6, 2018

Reviewed on December 4, 2018

Accepted on January 3, 2019

Published online on March 29, 2019

\begin{abstract}
Nowadays, the epidemic of obesity and metabolic syndrome can be observed not only among adults, but also amid the younger population, with more than 380 million children and adolescents worldwide being affected by these phenomena. Obesity is considered a systemic chronic metabolic disease resulting from the imbalance between energy intake and expenditure. The World Health Organization (WHO) has identified obesity as the most serious chronic disease, which, if untreated, leads to dangerous health problems (hypertension, heart failure, as well as kidney, nervous system and eye diseases). Recent scientific findings indicate a close relationship between obesity/metabolic syndrome and changes in the oral environment in children and adolescents. Obesity significantly increases the incidence of dental hard tissue diseases, periodontal diseases and diseases of the stomatognathic system. It also affects the secretion activity of the salivary glands, which changes the quantitative and qualitative composition of unstimulated and stimulated saliva. It is believed that in the face of a growing epidemic of obesity in children and adolescents, dental practitioners should also participate in the systemic treatment and prevention in this group of patients.
\end{abstract}

Key words: metabolic syndrome, obesity, children, oral cavity, dental problems

Słowa kluczowe: zespół metaboliczny, otyłość, dzieci, jama ustna, problemy stomatologiczne

Cite as

Salamonowicz MM, Zalewska A, Maciejczyk M. Oral consequences of obesity and metabolic syndrome in children and adolescents. Dent Med Probl. 2019;56(1):97-104. doi:10.17219/dmp/102620

DOI

$10.17219 / \mathrm{dmp} / 102620$

Copyright

๑ 2019 by Wroclaw Medical University

This is an article distributed under the terms of the

Creative Commons Attribution Non-Commercial License

(http://creativecommons.org/licenses/by-nc-nd/4.0/) 


\section{Introduction}

The World Health Organization (WHO) estimates that over 1.9 billion adults in the world are already overweight (body mass index $\left.(\mathrm{BMI})>25 \mathrm{~kg} / \mathrm{m}^{2}\right), 650$ million of whom are obese $\left(\mathrm{BMI}>30 \mathrm{~kg} / \mathrm{m}^{2}\right)$. More than 380 million children and adolescents worldwide are also affected by this phenomenon. In developing countries, $23.8 \%$ of boys and $22.6 \%$ of girls were overweight or obese in $2013 .{ }^{1}$ The WHO has identified obesity as the most serious chronic disease, which, if untreated, leads to dangerous health problems (hypertension, heart failure, as well as kidney, nervous system and eye diseases). Other health problems associated with obesity include type 2 diabetes mellitus (T2DM), lipid metabolism disorders, reflux, and obstructive sleep apnea. ${ }^{2,3}$ It has also been demonstrated that obese children experience psychological and psychosomatic problems such as depression, low self-esteem, eating disorders, and anxiety disorders much more frequently than their peers with normal body weight; furthermore, obese children are more likely to fall victim to social discrimination and bullying, which leads to the deterioration of the quality and comfort of their lives. ${ }^{4}$

The problem of metabolic disorders related to obesity and insulin resistance was first described in $1988 .{ }^{5}$ However, it was only 10 years later, in 1999, that the WHO and the European Group for the Study of Insulin Resistance (EGIR) proposed a definition of metabolic syndrome. It was assumed that, in addition to abdominal obesity, at least 2 other metabolic disorders listed by the International Diabetes Federation (IDF) must occur simultaneously for metabolic syndrome to be diagnosed: increased triglyceride (TG) concentration (>150 mg/dL), decreased concentration of high density lipoprotein (HDL) ( $<40 \mathrm{mg} / \mathrm{dL}$ for men and $<50 \mathrm{mg} / \mathrm{dL}$ for women), hypertension ( $\geq 130 / 85 \mathrm{~mm} \mathrm{Hg})$, T2DM, or impaired fasting glycemia (IFG) ( $\geq 100 \mathrm{mg} / \mathrm{dL})$. In adults, abdominal obesity is defined as excessive adipose tissue deposited in the abdomen and accompanied by negative health effects. For children and adolescents, abdominal obesity was defined based on waist circumference (WC) $\geq 90^{\text {th }}$ percentile value for age and sex. ${ }^{6}$ Obesity is considered a systemic chronic metabolic disease resulting from the imbalance between energy intake and expenditure, which is a very serious health problem due to its prevalence.

Recent scientific findings indicate a close relationship between obesity/metabolic syndrome and changes in the oral environment in children and adolescents. Obesity significantly increases the incidence of dental hard tissue diseases, periodontal diseases and diseases of the stomatognathic system. It also affects the secretion activity of the salivary glands, which changes the quantitative and qualitative composition of unstimulated and stimulated saliva. Therefore, the aim of this article was to review contemporary literature on oral implications of obesity and metabolic syndrome in children and adolescents.

\section{Obesity and periodontal disease}

Adipose tissue is considered not only spare material for the body, but also a biologically active organ. With significant accumulation, this tissue is believed to be the largest endocrine organ in the body. ${ }^{7,8}$ Obesity has been defined as a chronic inflammatory disease, in which the deposition of adipocytes may result in increased production of several cytokines, including tumor necrosis factor $\alpha$ (TNF- $\alpha$ ), interleukins (IL) IL-1 $\beta$, IL-6 and IL-8, and proinflammatory monocyte chemotactic protein-1 (MCP-1). ${ }^{9,10}$ This facilitates macrophage infiltration and contributes to the formation of a proinflammatory environment, also in the periodontium. ${ }^{11-13}$ Interleukin $1 \beta$ and IL- 8 are cytokines that stimulate the periodontal inflammatory processes. Interleukin $1 \beta$ stimulates $B$ and $\mathrm{T}$ type cells, endothelial cells, and, above all, osteoclasts, which results in the intensification of the bone resorption processes. ${ }^{14,15}$ Moreover, the stimulating effect on osteoclasts is demonstrated by TNF- $\alpha .{ }^{16,17}$ Interleukin 8 chemotactically affects granulocytes, the role of which is to release lysosomal enzymes and metalloproteinases (MMPs), involved in the degradation of the extracellular matrix of periodontal tissues. ${ }^{16,18}$ The activation of granulocytes also results in several dozen times higher oxygen consumption. This phenomenon is referred to as a respiratory burst and is aimed at the production and release of large amounts of superoxide anion radical and, consequently, other free oxygen radicals outside the cell. ${ }^{19} \mathrm{In}$ creased production of reactive oxygen species (ROS) with inadequate antioxidant response, observed in periodontal tissues of the obese, leads to the development of oxidative stress, ${ }^{20-22}$ which intensifies inflammatory changes in the periodontium. ${ }^{23}$

Adipocyte activity has been confirmed to influence the development and/or severity of periodontal disease. ${ }^{16,24-26}$ Furthermore, as shown by Reevez et al., even a 1-kilogram increase in body weight may increase the risk of periodontal disease by $6 \%$ in the group of obese teenagers over $17 .{ }^{27}$ Zhao et al. observed that in the absence of considerable differences in the clinical condition of the periodontium, obese children demonstrate a significant increase in TNF- $\alpha$ concentration in the gingival pocket fluid compared to children with normal body weight. ${ }^{28}$ This is confirmed by the results of the study by Lundin et al. ${ }^{29}$ Modéer et al. noted an increase in the concentration of proinflammatory interleukins (IL-1 $\beta$ and IL-8) in gingival pocket fluid of obese children compared to healthy subjects with normal body weight. ${ }^{30}$

The immunological disorders associated with obesity modify the bacterial flora of the subgingival plaque, which also predisposes obese patients to the occurrence of periodontal disease. Three times as many bacteria (of the 23 species included in the study) were found in obese teenagers as in their peers without overweight, and the amount of proteobacteria, Campylobacter rectus and 
Neisseria mucosa was even 6 times higher. However, the relationship between obesity and the number of bacteria in the subgingival plaque was not affected by the rate of saliva secretion, medications taken, chronic diseases, visible plaque index (VPI), bleeding on probing (BOP), or frequency of consumed meals. ${ }^{31}$

The number of scientific studies confirming the relationship between obesity and periodontitis in children and adolescents is low compared to the number of similar studies conducted among adults. In the study involving 12-year-old obese children, Sfasciotti et al. noted a significant increase in the full-mouth bleeding score (FMBS) (26.24\%) compared to children with normal body weight $(12.7 \%){ }^{8}$ In the study conducted by Modéer et al., the number of obese teenagers with BOP $<25 \%$ did not differ considerably from the number of peers with normal body weight, but there were significantly more obese adolescents with BOP $\geq 25 \%$ compared to those with normal body weight. ${ }^{25}$ The relationship between body weight and the periodontium condition was also found in the study involving adults. The study by Lehmann-Kalata et al. showed a statistically significant increase in the gingival index (GI) and sulcus bleeding index (SBI) values in obese people in comparison to those with normal body weight. ${ }^{32}$ The study by Zeigler et al. showed no correlation between BMI, dietary habits, hygiene, and oral hygiene in obese adolescents. ${ }^{33}$ However, obese teenagers with gingival pocket depth (PD) $\geq 4 \mathrm{~mm}$ had significantly more points with BOP $\geq 25 \%$ and considerably higher systolic blood pressure than obese teenagers with $\mathrm{PD}<4 \mathrm{~mm} .{ }^{33}$ This data may confirm the assumption that periodontal disease in obese adolescents has an impact on organ complications of obesity, leading to the development of arteriosclerosis and cardiovascular diseases. Also Scorzetti et al. noted a significant increase in the values of periodontal disease indicators, including the oral hygiene index $(\mathrm{OHI})$, approximal plaque index (API) and BOP, and a higher percentage of pockets with a probing depth exceeding $4 \mathrm{~mm}$ in obese children aged 6-13 compared to peers with normal body weight. ${ }^{24} \mathrm{Al}$ though none of the subjects showed a loss of connective tissue attachment (clinical attachment level $-\mathrm{CAL}) \geq 3$, the authors observed an increase in the CAL value in obese children compared to healthy controls. ${ }^{24}$ While studying adults, Saito et al. also observed that the number of people with deeper periodontal pockets increased with the increase in BMI. ${ }^{34}$ The researchers found a significant correlation between the waist-hip ratio (WHR) and BMI, and increased risk of periodontitis. ${ }^{34}$ However, Konopka et al. in their study involving 200 adults, did not find any relationship between the condition of the periodontium and BMI. ${ }^{35}$ The authors only demonstrated a higher API value in subjects with excessive body weight compared to slim people. ${ }^{35}$

It should be recalled that the intensification of inflammatory lesions in the periodontium was also observed in the course of obesity complicated by T2DM.
In the study by Janem et al., GI was significantly higher in obese children with T2DM than in obese children without diabetes and children with normal body weight aged 10-19.36 Diabetes, which is considered part of the metabolic syndrome, affects the periodontium condition through a variety of factors, including weakened function of neutrophils, activity of advanced glycation end products (AGEs), microangiopathies, and change in collagen metabolism. ${ }^{37}$ The study by Chacon et al. showed that the expression of monocytes after bacterial lipopolysaccharide (LPS) stimulation, manifested by increased production of TNF- $\alpha$ and IL- $1 \beta$, was much higher in patients with T2DM than in non-diabetic patients. ${ }^{38}$ Upon binding to AGEs, cells with receptor for advanced glycation end products (RAGE) on their surfaces, i.e., macrophages, monocytes and endothelial cells, increase the production of proinflammatory cytokines, permeability of blood vessels and oxidative stress. Excess free oxygen radicals can lead to tissue damage through, for instance, DNA damage. Excess AGEs also affect gingival fibroblasts by inhibiting the production of collagen and glycosaminoglycans by these cells. ${ }^{37}$ The study by Kumar et al. indicates that patients with periodontitis, but without metabolic disorders, have 3 times lower concentrations of MMP-9 and 2 times lower concentrations of MMP-8 than patients with periodontitis and diabetes. ${ }^{39}$ Increased concentrations of MMPs in the course of diabetes can lead to increased bone resorption.

\section{Obesity and dental hard tissue diseases}

Obesity and dental caries have many common causal factors, such as increased sugar intake, poor eating habits, ${ }^{40,41}$ and regular consumption of snacks and soft drinks. ${ }^{42}$ However, the results of studies on the relationship between metabolic syndrome or obesity and the prevalence of caries in children and adolescents are ambiguous. The studies by Gupta et al., ${ }^{43}$ Tong et al., ${ }^{44}$ Yen and $\mathrm{Hu},{ }^{45}$ and Hilt and Daszkowska ${ }^{46}$ demonstrated no correlation between the occurrence of caries and obesity, which is confirmed by the meta-analysis of data from the National Health and Nutrition Examination Survey (NHANES III and NHANES 1999-2002). ${ }^{47}$ Hilt and Daszkowska even found that in the group of adolescents with high BMI, the percentage of people free from caries was higher than in the group of teenagers with normal body weight. ${ }^{46}$ Gerdin et al. observed, however, that the prevalence of caries dropped with the increase in the socioeconomic status in each age group of children with overweight/obesity, while BMI of these children was unrelated to their socioeconomic status. ${ }^{48}$ The researchers also found that obese children with BMI > 30 had more teeth with caries than children with normal body weight $(\mathrm{BMI}<25)$, and that BMI correlated quite poorly with 
the decayed, missing and filled teeth (DMFT) index. Interestingly, Gerdin et al. also observed that children aged 5,7 and 10 with normal body weight, but overweight/ obese in the past (when aged 4), had significantly less caries than children aged 4-10 with normal body weight from birth. ${ }^{48}$ On the other hand, Willerhausen et al. noted that out of 1,290 primary school pupils, as many as $44.7 \%$ of children with underweight and $40.7 \%$ with normal body weight had healthy teeth without caries, while in the group of children with overweight and obesity, the rate was $30.5 \%$ and $31.7 \%$, respectively. ${ }^{49}$ Costacurta et al. observed a close relationship between tooth decay and obesity in children aged 6-11 resulting from a very high positive correlation between the DMFT index and the percentage of adipose tissue in the body (body fat mass - FM\%). ${ }^{41}$ The results of the aforementioned study ${ }^{41}$ are consistent with the observations of Modéer et al. ${ }^{25}$ and Gunjalli et al. ${ }^{50}$ Moreover, Bailleul-Forestier et al. found a positive correlation between BMI and the DMFT indicator. ${ }^{51}$ However, Alm et al. demonstrated that in the group of overweight 15-yearolds (age-specific BMI $\geq 25$ ), caries defects on the proximal surfaces were significantly more common and that regular consumption of sweet snacks and beverages in early childhood predisposes to a high risk of caries in 15-year-olds. ${ }^{42}$ Also, the study conducted by LehmannKalata et al. in a group of adults confirmed higher intensity of caries in obese people..$^{32}$ Pannunzio et al. ${ }^{52}$ suggest that decreased activity of salivary peroxidase (an enzyme responsible for the antibacterial and antioxidant properties of saliva ${ }^{53}$ ) may be the cause of increased incidence of caries in obese children. The said reduction of salivary peroxidase activity and the observed raised content of protein and free sialic acid (SA) in the saliva of obese people may lead to increased bacterial adhesion and colonization of the oral cavity by carious bacteria (Lactobacillus acidophilus and Streptococcus mutans). As a result, the rate of plaque creation may increase, which may lead to the formation of new caries defects in the future. This hypothesis is contradicted by the studies by Fadel et al. ${ }^{26}$ and Tong et al., ${ }^{44}$ as these researchers showed a similar microbiological profile and a comparable amount of carious bacteria in the saliva of obese children and children with normal body weight.

It is believed that both obesity and the severity of caries in children and adolescents are related to the education and economic status of their parents. Gerdin et al. demonstrated that parents of obese children with caries were less educated and in a worse socioeconomic situation than parents of children with normal body weight and without caries. ${ }^{48}$ It should also be remembered that children/teenagers often have sweet snacks between meals, which leads to the development of obesity and caries. Costacurta et al. found no differences in the frequency of sugar consumption with main meals, home and school oral hygiene, and the habit of eating after brushing teeth between children with normal body weight without caries, obese children without caries and obese children with caries. ${ }^{41}$ However, the group of obese children with caries was distinguished by higher frequency of sugar consumption between main meals, as well as higher intake of sweetened beverages. ${ }^{41}$

The existing literature contains data indicating the connection between obesity and the occurrence of tooth erosion in children and adolescents. Tong et al. believe that the teeth of obese children are less exposed to dental caries, but more susceptible to the development of noncarious cavities, i.e., erosion. ${ }^{44}$ It has been demonstrated that obese children are 26 times more likely to experience dental erosion than children with normal body weight. Erosion in obese children occurs mainly on the palatal surface of the incisors, while in children with normal body weight, it occurs on various tooth surfaces. What is more, obese children had a higher degree of tooth erosion, but not a higher number of eroded tooth surfaces compared to children with normal body weight. ${ }^{44}$ Increased dental erosion in obese children may result from excessive consumption of carbonated beverages, and in children on a slimming diet - from increased consumption of juices and energy drinks, as well as fruit, including citrus fruits. ${ }^{44}$ Other reasons for the intensification of erosive lesions include the use of chlorinated pools, induced vomiting and gastroesophageal reflux disease (GERD). Also, asthma may increase the incidence of dental erosion in children, which most probably results from the influence of therapy of this disease on the secretion and composition of saliva. ${ }^{54}$ The study by Pandolfino et al. confirmed the positive relationship between BMI and the risk of GERD. ${ }^{55}$

\section{Obesity and the stomatognathic system}

Obesity also affects the function of the respiratory system in children. Excessive adipose tissue in the thoracicabdominal region changes the mobility of the chest and diaphragm, which in turn reduces the maximum ventilation capacity and fixes a fast, shallow pattern of breathing. ${ }^{3}$ It has been proven that pressing the palate with fat cells results in decreased muscle tension, increased pharyngeal resistance and sleep apnea in obese people. Moreover, reduced thoracic cage compliance and an overload of the respiratory muscles interfere with breathing while sleeping. ${ }^{56}$ As evidenced by Marino et al., obese children suffering from obstructive sleep apnea have mild mandible retrognathia and increased skeletal divergency of the lower facial height. ${ }^{57}$ Increased pharyngeal resistance in children raises airflow through the mouth. The consequence of breathing through the mouth is an imbalance in the activity of the tongue, cheeks and lips (flaccid, incompetent lips). The lack of airflow through the nasal 
cavity entails the growth of the jaw and the formation of a narrow, high-arched palate. This leads to consequences of skeletal (development of skeletal Class II malocclusion), dental (front open bite, lateral crossbite, deep overjet), and facial (narrow nostrils, long face, incompetent lips) nature. ${ }^{58}$

Due to the increased release of growth hormone in the course of obesity ${ }^{59,60}$ and intensified secretion of leptin by adipose tissue, affecting cartilaginous growth centres, ${ }^{61}$ changes in skeletal and dental age are observed in obese children. These children present an earlier onset of puberty and shorter duration of puberty compared to the lean ones. ${ }^{61}$ It is commonly known that dental and skeletal age are the determinants of the starting point for the application of permanent braces, as well as the choice of an appropriate orthodontic treatment method in adolescent patients. While examining children between 7 and 15 years of age, Hilgers et al. found that dental age, according to Demirjian, was higher in obese and overweight children compared to that of children with normal weight. ${ }^{62}$ The study by Mack et al. demonstrated that each BMI percentile for a given age of a child means 0.005 years of growth for tooth age (which determines the stage of dentition development in relation to the metric age of a child). ${ }^{60}$ This means that the difference in tooth age between slim and obese children may be even several months (about 5 months) ${ }^{60}$ Moreover, it was observed that, in the period of mixed dentition, an obese child has approx. 1.44 times more teeth erupted than a child with normal body weight. ${ }^{63}$ Considering the fact that an accelerated rate of teeth eruption may significantly affect the oral health of children - from periodontal inflammation, through increased intensity of caries and occlusion defects, to diseases of the temporomandibular joint - the need for more frequent periodic evaluation of the oral cavity in overweight or obese children and adolescents should be stressed.

In obese children (especially girls), deviant craniofacial morphology is also observed. These changes concern mainly the length of the mandible, which is approx. $6 \mathrm{~mm}$ longer in obese girls and $8.7 \mathrm{~mm}$ longer in obese boys compared to their slim peers. Obese adolescents show not only an increased anterior cranial base length, but also greater maxillary and mandibular prognathism. ${ }^{61}$ Studies have shown that in obese teenagers, 13 years of age is most frequently the period of the peak growth of the mandible, which was not observed in a group of adolescents with normal body weight. ${ }^{60}$ Achieving the peak of mandible growth corresponding to Stage 3 of cervical vertebral maturation is the moment when the orthodontic treatment of skeletal Class II malocclusion should be started. ${ }^{64}$ Therefore, Mack et al. suggest that orthodontists, when planning treatment, should consider an earlier date of its commencement in obese patients with skeletal Class II malocclusion compared to patients with normal body weight. ${ }^{60}$ In the study involving a group of teenagers with fixed braces, Saloom et al. found that obese adolescents had a significantly higher rate of tooth movement over the period of alignment than those with normal body weight. ${ }^{65}$

\section{Changes in the quantitative composition of saliva in obese children}

Saliva is a secretion of the salivary glands that provides a fluid environment for the oral ecosystem. Saliva moisturizes oral tissues, enables articulation and initial digestion of food, as well as swallowing, and protects the surface of the teeth and mucous membranes against biological, mechanical and chemical factors. ${ }^{66}$ The proper activity of the salivary glands is essential for all these saliva functions. It is clinically proven to occur when unstimulated saliva is at a level of $>0.2 \mathrm{~mL} / \mathrm{min}$ and stimulated saliva is at a level of $>0.7 \mathrm{~mL} / \mathrm{min}$. Despite the undoubtedly leading role of proper saliva secretion in maintaining oral homeostasis, the number of available scientific analyses concerning saliva secretion in children and adolescents with overweight/obesity problems is still low.

The results of the studies by Modéer et al. ${ }^{25}$ and Fadel et al. ${ }^{26}$ revealed a significant decrease in the secretion of stimulated saliva in obese teenagers (aged 10-18) compared to their peers without overweight, which was contrary to the reports of Pannunzio et al., who focused on the secretion of stimulated saliva in a group of children up to 10 years of age. ${ }^{52}$ In the study by Fadel et al., the reduction of stimulated saliva secretion corresponded to the increase in BMI, which may suggest that the secretion activity of the salivary glands is impaired by increased body weight. ${ }^{26}$ Also, the results of the study conducted in a group of adults by Lehmann-Kalata et al. confirmed decreased stimulated and unstimulated saliva secretion in obese people compared to those with normal body weight. $^{32}$ In the study conducted by Rodríguez et al., ${ }^{67}$ the secretion of unstimulated saliva, and in the study of de Campos et al., ${ }^{68}$ the secretion of both unstimulated and stimulated saliva did not differ significantly in the group of obese children and children with normal body weight. However, Rodríguez et al. observed that unstimulated saliva secretion was considerably higher in obese girls than in obese boys, which was not observed in a group of adolescents with normal body weight. ${ }^{67}$

The mechanisms by which obesity affects saliva production have not been fully examined. A significant degree of steatosis of the parotid glands of obese patients has been demonstrated in the absence of pathological morphological changes in the submandibular glands. ${ }^{69}$ It is well-accepted that human parotid glands produce saliva mainly upon stimulation, while the submandibular glands provide unstimulated saliva. ${ }^{70-73}$ Therefore, it is believed 
that changes in the composition or secretion of stimulated saliva signal abnormalities in the function of the parotid glands. Similarly, the dysfunction of the submandibular glands is connected with changes in unstimulated saliva secretion. In the parenchyma of the parotid glands there are adipocytes that stimulate the expression of proinflammatory cytokines, like tumor growth factor $\beta 1$ (TGF- $\beta 1$ ), IL-1, and, through ROS-mediated stimulation, the Akt- $\mathrm{kB}$ signalling pathway activates MMPs. DNA synthesis and the expression of $\mathrm{Na}^{+} / \mathrm{K}^{+}$ATPase are hindered by TGF- $\beta 1$, which negatively affects epithelial proliferation. ${ }^{74}$ Increased activity of MMPs results in inflammation and the reconstruction of extracellular matrix. These factors are known to lead to decreased response of residual acinar cells to noradrenaline (NA) and acetylcholine (ACh), or receptor reconstruction. All these processes may result in diminished secretion of stimulated saliva and a weakened mechanism of protein synthesis/secretion, which is the phenomena that we observed in the saliva of obese adult patients. $^{75}$

\section{Summary}

Childhood obesity is a complex and multidisciplinary clinical problem that is of interest to physicians of various specialities (including dentists). Recently, more attention has been paid to the metabolic consequences of obesity within the oral cavity, including increased incidence of caries and periodontal diseases, diseases of the stomatognathic system, as well as impaired saliva secretion and changes in its biochemical composition. It is believed that in the face of a growing epidemic of obesity in children and adolescents, dental practitioners should participate in the systemic treatment and prevention in this group of patients. Numerous changes in the oral cavity (e.g., caries, periodontal diseases) have a common etiological background stemming from metabolic obesity disorders. These include excessive consumption of sugars, sweetened beverages and fast food snacks. It is well-known that adipose tissue does not only store energy, but is also a biologically active organ influencing the hormonal and mineral metabolism, as well as the activity of children's immune system. Changes in the immune system (increase in proinflammatory cytokine secretion) may affect the condition of the periodontium, and - along with poor hygiene in obese children - also cause chronic systemic inflammation. Due to hormonal changes causing accelerated skeletal and dental growth, overweight/obese children and adolescents should be regularly examined by orthodontists.

\section{ORCID iDs}

Małgorzata Maria Salamonowicz (D) https://orcid.org/0000-0003-1882-1520 Anna Zalewska (i) https://orcid.org/0000-0003-4562-0951 Mateusz Maciejczyk (D) https://orcid.org/0000-0001-5609-3187

\section{References}

1. Haegele JA, Healy S, Zhu X. Physical activity and obesity among nine-year-old children with and without chronic health problems, illness, or disabilities in Ireland. Disabil Health J. 2018;11(1):143-148.

2. Pogodina A, Rychkova L, Kravtzova O, Klimkina J, Kosovtzeva A. Cardiometabolic risk factors and health-related quality of life in adolescents with obesity. Child Obes. 2017;13(6):499-506.

3. Fitzgerald DA. The weighty issue of obesity in paediatric respiratory medicine. Paediatr Respir Rev. 2017;24:4-7.

4. Sagar R, Gupta T. Psychological aspects of obesity in children and adolescents. Indian J Pediatr. 2017;85(7):554-559.

5. Reaven GM. Banting lecture 1988. Role of insulin resistance in human disease. Diab. 1988;37(12):1595-1607.

6. Bassali R, Waller JL, Gower B, Allison J, Davis CL. Utility of waist circumference percentile for risk evaluation in obese children. Int J Pediatr Obes. 2010;5(1):97-101.

7. Mohamed-Ali V, Pinkney JH, Coppack SW. Adipose tissue as an endocrine and paracrine organ. Int $J$ Obes Relat Metab Disord. 1998;22(12):1145-1158.

8. Sfasciotti GL, Marini R, Pacifici A, lerardo G, Pacifici L, Polimeni A. Childhood overweight-obesity and periodontal diseases: Is there a real correlation? Ann Stomatol (Roma). 2016;7(3):65-72.

9. Wisse BE. The inflammatory syndrome: The role of adipose tissue cytokines in metabolic disorders linked to obesity. J Am Soc Nephrol. 2004;15(11):2792-2800.

10. Trayhurn P, Wood IS. Adipokines: Inflammation and the pleiotropic role of white adipose tissue. Br J Nutr. 2004;92(3):347-355.

11. Dursun E, Akalin FA, Genc T, Cinar N, Erel O, Yildiz BO. Oxidative stress and periodontal disease in obesity. Medicine (Baltimore). 2016;95(12):e3136.

12. Leite RS, Marlow NM, Fernandes JK. Oral health and type 2 diabetes. Am J Med Sci. 2013;345(4):271-273.

13. D'Aiuto F, Nibali L, Parkar M, Patel K, Suvan J, Donos N. Oxidative stress, systemic inflammation, and severe periodontitis. J Dent Res. 2010;89(11):1241-1246.

14. Huynh NC, Everts V, Pavasant P, Ampornaramveth RS. Interleukin-1ß induces human cementoblasts to support osteoclastogenesis. Int J Oral Sci. 2017;9(12):e5.

15. Gowen M, Wood DD, Ihrie EJ, McGuire MK, Russell RG. An interleukin 1 like factor stimulates bone resorption in vitro. Nature. 1983;306(5941):378-380.

16. Khosravi R, Ka K, Huang $T$, et al. Tumor necrosis factor-alpha and interleukin-6: Potential interorgan inflammatory mediators contributing to destructive periodontal disease in obesity or metabolic syndrome. Mediators Inflamm. 2013;2013:728987.

17. Kobayashi K, Takahashi N, Jimi E, et al. Tumor necrosis factor alpha stimulates osteoclast differentiation by a mechanism independent of the ODF/RANKL-RANK interaction. J Exp Med. 2000;191(2):275-286.

18. Mukaida N. Interleukin-8: An expanding universe beyond neutrophil chemotaxis and activation. Int J Hematol. 2000;72(4):391-398.

19. Sarniak A, Lipińska J, Tytman K, Lipińska S. Endogenous mechanisms of reactive oxygen species generation. Postepy Hig Med Dosw (Online). 2016;70(0):1150-1165.

20. Knaś M, Maciejczyk M, Waszkiel D, Zalewska A. Oxidative stress and salivary antioxidants. Dent Med Probl. 2013;50(4):461-466.

21. Lushchak VI. Free radicals, reactive oxygen species, oxidative stress and its classification. Chem Biol Interact. 2014;224:164-175.

22. Lushchak VI. Classification of oxidative stress based on its intensity. EXCLI J. 2014;13:922-937.

23. Öngöz Dede F, Bozkurt Doğan Ş, Ballı U, Avcı B, Durmuşlar MC. The effect of initial periodontal treatment on plasma, gingival crevicular fluid and salivary levels of 8-hydroxy-deoxyguanosine in obesity. Arch Oral Biol. 2016;62:80-85.

24. Scorzetti L, Marcattili D, Pasini M, Mattei A, Marchetti E, Marzo G. Association between obesity and periodontal disease in children. Eur J Paediatr Dent. 2013;14(3):181-184.

25. Modéer T, Blomberg CC, Wondimu B, Julihn A, Marcus C. Association between obesity, flow rate of whole saliva, and dental caries in adolescent. Obesity. 2010;18(12):2367-2373.

26. Fadel HT, Pliaki A, Gronowitz E, et al. Clinical and biological indicators of dental caries and periodontal disease in adolescents with or without obesity. Clin Oral Investig. 2014;18(2):359-368. 
27. Reeves AF, Rees JM, Schiff M, Hujoel P. Total body weight and waist circumference associated with chronic periodontitis among adolescents in the United States. Arch Pediatr Adolesc Med. 2006;160(9):894-899.

28. Zhao B, Jin C, Li L, Wang Y. Increased expression of TNF-a occurs before the development of periodontitis among obese Chinese children: A potential marker for prediction and prevention of periodontitis. Oral Health Prev Dent.2016;14(1):71-75.

29. Lundin M, Yucel-Lindberg T, Dahllöf G, Marcus C, Modéer T. Correlation between TNFalpha in gingival crevicular fluid and body mass index in obese subjects. Acta Odontol Scand. 2004;62(5):273-277.

30. Modéer T, Blomberg C, Wondimu B, Lindberg TY, Marcus C. Association between obesity and periodontal risk indicators in adolescents. Int J Pediatr Obes. 2011;6(2-2):e264-e270.

31. Zeigler CC, Persson GR, Wondimu B, Marcus C, Sobko T, Modéer T. Microbiota in the oral subgingival biofilm is associated with obesity in adolescence. Obesity (Silver Spring). 2012;20(1):157-164.

32. Lehmann-Kalata AP, Surdacka A, Ciężka-Hsiao E, Swora-Cwynar E, Grzymisławski M. Clinical parameters of oral cavity, physical and microbiological properties of saliva in patients with obesity [in Polish]. Dent Med Probl. 2015;52(4):415-423.

33. Zeigler CC, Wondimu B, Marcus C, Modéer T. Pathological periodontal pockets are associated with raised diastolic blood pressure in obese adolescents. BMC Oral Health. 2015;15:41.

34. Saito T, Shimazaki $Y$, Koga T, Tsuzuki M, Ohshima A. Relationship between upper body obesity and periodontitis. J Dent Res. 2001;80(7):1631-1636

35. Konopka T, Matuszewska A, Chrzęszczyk D, Zawada Ł. Body mass index and selected periodontal clinical parameters [in Polish] Dent Med Probl. 2011;48(2):189-197.

36. Janem WF, Scannapieco FA, Sabharwal A, et al. Salivary inflammatory markers and microbiome in normoglycemic lean and obese children compared to obese children with type 2 diabetes. PLoS One. 2017;12(3):e0172647.

37. Melkowska M, Banach J. Pathomechanisms of periodontal tissue alterations in diabetes mellitus - the literature review. Dent Med Probl. 2009(1);46:104-109.

38. Chacon MR, Vendrell J, Miranda M, et al. Different TNFalpha expression elicited by glucose in monocytes from type 2 diabetes mellitus patients. Atheroscler. 2007;194(2):e18-e25.

39. Kumar MS, Vamsi G, Sripriya R, Sehgal PK. Expression of matrix metalloproteinases (MMP-8 and -9) in chronic periodontitis patients with and without diabetes mellitus. J Periodontol. 2006;77(11):1803-1808.

40. Tinanoff N, Holt K. Introduction to proceedings of healthy futures: Engaging the oral health community in childhood obesity prevention national conference. J Public Health Dent. 2017;77(Suppl 1):S5-S7.

41. Costacurta M, DiRenzo L, Sicuro L, Gratteri S, De Lorenzo A, Docimo R. Dental caries and childhood obesity: Analysis of food intakes, lifestyle. Eur J Paediatr Dent. 2014;15(4):343-348.

42. Alm A, Fåhraeus C, Wendt LK, Koch G, Andersson-Gäre B, Birkhed D. Body adiposity status in teenagers and snacking habits in early childhood in relation to approximal caries at 15 years of age. Int J Paediatr Dent. 2008;18(3):189-196.

43. Gupta P, Gupta N, Singh HP. Prevalence of dental caries in relation to body mass index, daily sugar intake, and oral hygiene status in 12-year-old school children in Mathura city: A pilot study. Int J Pediatr. 2014;2014:921823.

44. Tong HJ, Rudolf MC, Muyombwe T, Duggal MS, Balmer R. An investigation into the dental health of children with obesity: An analysis of dental erosion and caries status. Eur Arch Paediatr Dent. 2014;15(3):203-210.

45. Yen CE, Hu SW. Association between dental caries and obesity in preschool children. Eur J Paediatr Dent. 2013;14(3):185-189.

46. Hilt A, Daszkowska M. Dental status of normal and overweight persons from secondary schools of Lodz [in Polish]. Dent Med Probl. 2012;49(3):351-357.

47. Kopycka-Kedzierawski DT, Auinger P, Billings RJ, Weitzman M. Caries status and overweight in 2- to 18-year-old US children: Findings from national surveys. Community Dent Oral Epidemiol. 2008;36(2):157-167.

48. Gerdin EW, Angbratt M, Aronsson K, Eriksson E, Johansson I. Denta caries and body mass index by socio-economic status in Swedish children. Community Dent Oral Epidemiol. 2008;36(5):459-465.
49. Willerhausen B, Blettner M, Kasaj A, Hohenfellner K. Association between body mass index and dental health in 1,290 children of elementary schools in a German city. Clin Oral Investig. 2007;11(3):195-200.

50. Gunjalli G, Kumar KN, Jain SK, Reddy SK, Shavi GR, Ajagannanavar SL. Total salivary anti-oxidant levels, dental development and oral health status in childhood obesity. J Int Oral Health. 2014;6(4):63-67.

51. Bailleul-Forestier I, Lopes K, Souames M, Azoguy-Levy S, Frelut ML, Boy-Lefevre ML. Caries experience in a severely obese adolescent population. Int J Paediatr Dent. 2007;17(5):358-363.

52. Pannunzio E, Silverio Amancio OM, de Souza Vitalle MS, Nesadal de Souza D, Medeiros Mendes F, Nicolau J. Analysis of the stimulated whole saliva in overweight and obese children. Rev Assoc Med Bras. 2010;56(1):32-36.

53. Reznick AZ, Klein Y, Eisfrich JP, Cross EC, Nagler RM. Inhibition of oral peroxidase activity by cigarette smoke: In vivo and in vitro studies. Free Radic Biol Med. 2003;34(3):377-384.

54. Adamowicz A, Bręborowicz A, Borysewicz-Lewicka M. Dental erosion in children with asthma [in Polish]. Dent Med Probl. 2009:46(2):185-190.

55. Pandolfino JE, El-Serag HB, Zhang Q, Shah N, Ghosh SK, Kahrilas PJ. Obesity: A challenge to esophagogastric junction integrity. Gastroenterology. 2006;130(3):639-649.

56. Mallory GB Jr, Fiser DH, Jackson R. Sleep-associated breathing disorders in morbidly obese children and adolescents. J Pediatr. 1989;115(6):892-897.

57. Marino A, Malagnino I, Ranieri R, Villa MP, Malagola C. Craniofacial morphology in preschool children with obstructive sleep apnoea syndrome. Eur J Paediatr Dent. 2009;10(4):181-184.

58. Enache AM, Nimigean VR, Mihălţan F, Didilescu AC, Munteanu I, Nimigean V. Assessment of sagittal and vertical skeletal patterns in Romanian patients with obstructive sleep apnea. Rom J Morphol Embryol. 2010;51(3):505-508.

59. Favero L, Arreghini A, Cocilovo F, Favero V. Respiratory disorders in paediatric age: Orthodontic diagnosis and treatment in dysmetabolic obese children and allergic slim children. Eur J Paediatr Dent. 2013;14(3):190-194.

60. Mack KB, Phillips C, Jain N, Koroluk LD. Relationship between body mass index percentile and skeletal maturation and dental development in orthodontic patients. Am J Orthod Dentofacial Orthop. 2013;143(2):228-234.

61. Olszewska K, Ważna-Olszewska M, Dunin-Wilczyńska I. Obesity in children and adolescents - a new challenge in orthodontic practice. Dent Med Probl. 2015;52(2):131-136.

62. Hilgers KK, Akridge M, Scheetz JP, Kinane DE. Childhood obesity and dental development. Pediatr Dent. 2006;28(1):18-22.

63. Must A, Phillips SM, Tybor DJ, Lividini K, Hayes C. The association between childhood obesity and tooth eruption. Obesity (Silver Spring). 2012;20(10):2070-2074.

64. Baccetti T, Franchi L, McNamara JA Jr. The cervical vertebral maturation (CVM) method for the assessment of optimal treatment timing in dentofacial orthopedics. Semin Orthod. 2005;11:119-129.

65. Saloom HF, Papageorgiou SN, Carpenter GH, Cobourne MT. Impact of obesity on orthodontic tooth movement in adolescents: A prospective clinical cohort study. J Dent Res. 2017;96(5):547-554.

66. Waszkiewicz N, Zalewska A, Szulc A, et al. The influence of alcohol on the oral cavity, salivary glands and saliva [in Polish]. Pol Merkur Lekarski. 2011;30(175):69-74.

67. Rodríguez PN, Martínez Reinoso J, Gamba CA, et al. Association among salivary flow rate, caries risk and nutritional status in preschoolers. Acta Odontol Latinoam. 2015;28(2):185-191.

68. de Campos MM, Kobayashi FY, Barbosa TdS, da Silva Costa S, de Lima Lucas B, Castelo PM. Characteristics of salivary secretion in normal-weight, overweight and obese children: A preliminary study. Salivary composition and excessive fat tissue. Odontology. 2014;102(2):318-324.

69. Bozzato A, Burger P, Zenk J, Ulter W, Iro H. Salivary gland biometry in female patients with eating disorders. Eur Arch Otorhinolaryngol. 2008;265(9):1095-1102.

70. Dawes C. Salivary flow patterns and the health of hard and soft oral tissues. J Am Dent Assoc. 2008;139(Suppl):18S-24S.

71. Knaś M, Zalewska A, Waszkiewicz N, et al. Salivary: Flow and proteins of the innate and adaptive immunity in the limited and diffused systemic sclerosis. J Oral Pathol Med. 2014;43(7):521-529. 
72. Nagler RM. Salivary glands and the aging process: Mechanistics aspects, health status and medicinal efficacy monitoring. Biogerontology. 2004;5(4):223-233.

73. Zalewska A, Knaś M, Gińdzieńska-Sieśkiewicz E, et al. Salivary antioxidants in patients with systemic sclerosis. J Oral Pathol Med. 2014:43(1):61-68.

74. Bursch W, Obenhammer F, Jirtle RL, et al. Transforming growth factor 1 as a signal for induction of cell death by apoptosis. Br J Cancer. 1993;67(3):531-536.

75. Knaś M, Maciejczyk M, Sawicka K, et al. Impact of morbid obesity and bariatric surgery on antioxidant/oxidant balance of the unstimulated and stimulated saliva. J Oral Pathol Med. 2016;45(6):455-464. 